Article

\title{
Promotion of Shared Value for the SDGs (Sustainable Development Goals): A Case Study of Australia
}

Jae-Eun Noh

School of Social Work and Human Services, The University of Queensland, Brisbane, St Lucia QLD 4072, Australia; Email: jaeeun.noh@uqconnect.edu.au

\begin{abstract}
Background: The Sustainable Development Goals (SDGs) recognize the key role of business in achieving targets. Corporations have embraced the strategy of "Creating Shared Value (CSV)" to enhance corporate competitiveness and profitability while working on social and environmental issues. Despite substantial acclaim for synergy of integrating the SDGs and the concept of shared value, the linkage between the SDGs and CSV is under-researched. This present study aims to examine how CSV and the SDGs are understood and pursued in relation to each other.
\end{abstract}

Methods: This research employed a case study design. Documents of the Australian Government, companies and civil society were thematically analyzed to understand the conceptualization and operationalization of CSV in the Australian context.

Results: Findings suggest that the SDGs are well-aligned with the values held by the Australian Government and citizens. Relative to the SDGs, Australian companies have framed their CSV closely but operationalization of shared value still needs a stronger connection with the SDGs. Key themes were the necessity for incentives and support for companies, the government's leadership and coordination role, and participation of civil society.

Conclusions: This case study presented the potential of CSV for attainment of the SDGs and corporate sustainability. Societal commitment to core values such as human rights and equality may be the key to SDG-CSV harmonization and multi-stakeholder collaboration.

Received: 31 March 2020

Accepted: 22 May 2020

Published: 25 May 2020

Copyright $(0) 2020$ by the author(s). Licensee Hapres, London, United Kingdom. This is an open access article distributed under the terms and conditions of Creative Commons Attribution KEYWORDS: shared value; sustainable development goals (SDGs); private sector; Australia

\section{ABBREVIATIONS}

SDGs, Sustainable Development Goals; CSV, creating shared value; CSR, corporate social responsibility

4.0 International License. 


\section{INTRODUCTION}

The Sustainable Development Goals (SDGs), adopted by 193 UN member states in 2015, included an agenda of shared value, which emphasizes the role of the private sector as well as conventional development actors. "Creating shared value (CSV)" is a business strategy which addresses societal needs and challenges while enhancing competitive advantage and profitability [1]. The concept of shared value can strengthen the role of companies in advancing sustainable development without losing profitability. The discussion of shared value has been dominated by the business sector [2]. Given the concept of shared value includes social and environmental values as well as economic values [3], the SDGs can be useful for operationalization of shared value, which is lacking an implementation framework and evaluation indicators. In fact, some corporations have utilized SDGs' 16 goals and 169 targets to analyze enabling or constraining social issues and to measure shared value [3]. Further, the SDGs are suggested as useful for fostering organisational learning in the business sector [4]. As both the SDGs and CSV emerged recently, research on the nexus of the two is limited. A recent survey of 325 engineers in the UK revealed the difficulty in defining and measuring shared value in relation to the SDGs [5]. Another research article suggests benefits and synergies from combining the SDGs and CSV drawing on sustainability reports published by corporations based in East Asia [6].

Acknowledging some corporations' instrumental approach to the SDGs, this article aims to understand how development actors can utilize the concept of shared value to advance the SDGs without undermining social values such as human rights and equality. It should be noted that corporate values including shared value have had an influence on the SDGs and their social values, as seen in a critique of pro-market ideological shifts in human rights discourse [7] and the SDGs' roots in neoliberalism [8,9]. Another thing to consider is the importance of context in which the SDGs are implemented. Global frameworks such as the SDGs are often criticized as a superpower-driven production which promotes de-historicization, de-politicization and simplification [10].

This article hereby employs a case study of Australia to explore how a government, as a conventional development actor, and corporations, as emerging development actors, are translating shared value into practice to achieve the SDGs, paying attention to contextual influences. The Australian government submitted the Voluntary National Review in 2018 and the Report on UN Sustainable Development Goal in 2019, which reflect its effort to align the national plan with the SDGs. These reports mention the Shared Value Project as an example of working with the business sector in partnership. The Shared Value Project was established in 2014 to advance shared value in Australia and the Asia Pacific as the peak body of companies, government agencies and civil society. It has advocated shared value by educating companies and hosting events such 
as the Shared Value Summit in 2019. Australian companies recognize the SDGs as a change driver and identify income inequality and biodiversity loss as key areas to work on [11].

The overarching goal of this research is to explore how shared value is perceived and practiced in relation to the SDGs and social values held by the Australian society. The research questions to address are whether and how shared value is pursued in line with the SDGs in Australia and whether there is any difference in perceptions and practice between the government and businesses. The following discussion builds from previous research on corporate social responsibility (CSR) and the emergence of shared value in relation to international development discourses. Then, social values highlighted in SDGs are presented in comparison with MDGs (Millennium Development Goals). It is essential to clarify how CSV is understood in relation to the existing concept of CSR and how the SDGs involve private companies differently from the MDGs. Therefore, the distinction and convergence of these concepts will be examined.

\section{Corporate Social Responsibility (CSR) and Creating Shared Value (CSR)}

CSR has been extensively discussed since 1990 [12]. Although there is no single definition of CSR, its key feature is integrating social and environmental concerns into business operation [13]. Companies have incorporated CSR to improve brand image, increase loyalty of consumers and employees, and adopt innovative ideas [14,15]. Therefore, CSR performance has been measured by customer evaluation, corporate reputation and employee morale [16,17]. International development actors have advocated for CSR in expectation of a decrease in companies' negative influences on the livelihood of people and environment. However, CSR has not been very effective in improving business practice, as it relies on consumers' power mainly in rich countries or corporations' voluntary regulations [18]. For example, the responsibilities to comply with voluntary regulatory schemes such as the International Organization for Standardization (ISO) or the United Nations Global Compact are often used selectively or transferred by a supply chain to small companies [14,19,20].

Shared value centers around a synergy between business activities and wider benefits to society and the environment [1]. Creating Shared Value (CSV) is a new business strategy based on the idea that corporate competitiveness and profit making can be enhanced when companies take care of the social and environmental needs of the community in which they work. Communities' social and environmental needs lead to identification and creation of markets, and their unmet needs can increase costs of business operations [1]. Research on shared value has been dominated by business disciplines. A systematic review of shared value indicates that only about $5 \%$ of reviewed articles were published 
by non-business journals [21]. In business studies, shared value tends to be understood as a concept building on the Triple Bottom Line (3P: profit, people, and planet) and SDGs as a management tool for CSV [5]. However, shared value is under-researched in development studies. The reviewed literature, although scarce, suggests CSV as a public-private partnership (PPP) model for international development [22].

The relationship between CSR and CSV is diversely understood. Some regard CSV as one of the management strategies for CSR [2], as CSR is an umbrella concept which has evolved through the addition of new focuses and ideas to improve business practice [23]. Others distinguish CSV from CSR, paying attention to differences between the two-CSR is pushed from outside as a normative agenda with an additional consideration of social values, whilst CSV is internally generated to pursue profits through connecting business to social values [24]. Acknowledging that there is no clear distinction between shared value and related concepts including CSR [21], this study attempts to understand how diversely shared value is conceptualized.

\section{SDGs-Emphases on Social Values and Business Engagement}

The Millennium Development Goals (MDGs), which range from poverty eradication to global partnership with time-bound targets established in 2000, were replaced by the SDGs in 2015. Differently from the MDGs, the SDGs emphasize participation of business for sustainable growth, as highlighted in Goal 8 [25,26]. The SDGs embrace environmental concerns in addition to economic and social concerns. They also strengthen underlying values such as human rights, reduced inequality and climate justice as follows.

Firstly, the SDGs' alignment with human rights is noticeable. The SDGs seek to realize the human rights of all (Preamble) and they are grounded in the Universal Declaration of Human Rights and international human rights treaties (Article 10). "The SDGs are to be implemented in a manner that is consistent with the rights and obligations of states under international law" (Article 18) means that international human rights law can provide guidance when no domestic legal procedure exists. In this way, most goals and targets reflect human rights standards even when human rights language was not explicitly used [27,28]. For example, the SDGs cover civil and political rights such as governance, rule of law and access to justice as well as social and economic rights including education, health, food, water and sanitation.

Secondly, the SDGs emphasize the importance of reducing inequality. While the MDGs mainly cover issues of so-called developing countries, the SDGs are applicable to all countries with an emphasis on inequality and exclusion [29]. The SDGs challenge power imbalances to deal with underlying and structural issues [30]. In the SDGs, expressions like "inclusive", "equitable", "for all", and "in all forms" are frequently used. For example, the SDGs promise to "end poverty in all its forms 
everywhere", while the MDGs aimed to "eradicate extreme poverty and hunger". When it comes to education, "to ensure inclusive and equitable quality education and promote lifelong learning opportunities for all" is pursued in the SDGs, going far beyond the narrow vision of "to achieve universal primary education" in the MDGs. Reducing inequality is not confined to Goal 10, but is related to every goal of SDGs.

Thirdly, it is apparent that many of the SDGs are environmental in focus. Environment-related goals are embedded in the SDGs, building on environmental agenda discussed at Rio+20 in 2012. The SDGs' emphasis on environmental sustainability raised the question of how to connect with human rights. Some articles suggest the linkage between the two: for example, every human being has a right to live in a stable environment and climate change is a threat to rights to life, health and subsistence [31]. However, there is a call for an innovative view of the relationship between human rights and environmental discourses beyond a human-centered approach [32].

These social values highlighted in the SDGs are not new to businesses. The Global Reporting Initiative (GRI), established in 1997, claimed the necessity of embracing sustainability in company reports. The UN Global Compact, proposed by Kofi Annan in 1999, was an initiative to make companies accountable to society [10]. Its ten principles embody corporate sustainability in the areas of human rights, labor, environment and anti-corruption. The GRI and the Global Compact are working in collaboration to promote "Business Reporting on SDGs". Adoption of SDG reporting is positively associated with a company's size, level of commitment to sustainability, and percentage of female or young directors [33]. Some critically view that integrating business practice with SDGs is possible as the SDGs were set under corporations' policy influence. The SDGs were informed by the neoliberal notion of development such as free trade and investment, which suit corporations' self-interest $[8,9]$. The development of the SDGs can be understood as part of the global order which reduces development to economic progress alone [34]. As a result, the SDGs describe inequality as a natural condition, not a socially constructed problem, and turn human rights from entitlement to a matter of access [9]. This study attends to the possible tensions between the SDGs' underlying values and corporations' neoliberal approach to the SDGs.

\section{MATERIALS AND METHODS}

Theories on system and organizations informed an understanding of change drivers for SDGs and CSV. Both theories regard an organization and its external context to be connected and inter-dependent. System theories draw attention to the environmental impacts on an organization and organizational theories focus on internal changes through management mechanism [35,36]. In this study, changes in Australian government and corporations are understood as adaptation to changing 
situations as noted by system theories and as voluntary strategies to deal with the contexts in line with organizational theories [37].

This theoretical orientation led me to adopt a qualitative case study. A case study is appropriate to explore current events which cannot be isolated from the contextual conditions [38]. This present study was designed to elicit the social construction of Australian government and companies to illuminate how they understood and practiced shared value in relation to the SDGs and their underpinning social values. Data were collected from key documents including "2019 Report on UN Sustainable Development Goals”, submissions to the inquiry into the SDGs, webpages and publications by "the Shared Value Project", and reports published by companies mentioned as examples in the report or relevant websites (Table 1). The 2019 Report, in particular Chapters 1, 2 and 5, is the main source as it shows Australian government's understanding of the SDGs and shared value and also includes diverse stakeholders' views based on submissions written by companies, non-governmental organizations, and academics. Additional data from the Shared Value Project and Australian companies provide companies' perceptions and operationalization of shared value.

Table 1. Documents and websites list.

\begin{tabular}{llll}
\hline Ref & Year & Source & Title \\
\hline A & 2019 & Parliament of Australia & Report on UN Sustainable Development Goals \\
B & 2019 & Shared Value Project (SVP) & The State of Shared Value in Australia and New Zealand in 2019 \\
C & 2019 & Bendigo and Adelaide Bank & Annual Review 2018 \\
D & 2018 & Parliament of Australia & Submission 17 \\
E & 2018 & Parliament of Australia & Submission 49 \\
F & 2018 & Cardno & Sustainability in action: Australian mining and the UN Sustainable \\
& & & Development Goals \\
G & 2015 & Shared Value Project & The State of Shared Value in Australia \\
H & NA & Shared Value Project (Website) & Case studies, about the SVP \\
I & NA & Mineral Council of Australia (Website) & The Enduring Value Framework \\
\hline
\end{tabular}

These documents were thematically analyzed using NVivo. Descriptive codes were produced by repeated reading and assigning passages, and then descriptive codes were clustered to identify themes, seeking a higher level of abstraction and generalization [39]. For example, a theme of "Australian context" was developed from several codes such as "Australian values", "awareness" and "indigenous people". Major themes such as "need for CSV in the SDG era" and "CSV in practice" arose in relation to key concepts of shared value and the SDGs. The former theme involved diverse perspectives of CSV, and the latter theme was mainly drawn from corporates' experience. Given that documents are social products [40], each document's intended reader and purpose as well as the contents were considered for analysis. To ensure trustworthiness, descriptions of good corporate practice were searched 
from multiple sources and contradictions between documents were reported to reflect the complexity of reality. For example, different viewpoints on the state of shared value in Australia was noted.

\section{RESULTS}

\section{SDGs’ Relevance to Australia}

The 2019 Report on the UN Sustainable Development Goals (SDG) noted that core values of the SDGs are well aligned with Australian values such as cooperation, a fair go, being a good neighbor and gender equality (A). This is well captured by a quote from the United Nations Association of Australia stating that "the SDGs is a demonstration of our true national values. Only the branding name of the SDGs is new for Australia” (A, p. 13). The Report also emphasized Australia's contribution toward the establishment of the SDGs, particularly for economic growth (SDG 8), peace and good governance (SDG 16), sustainable use of the oceans (SDG 14), and gender equality (SDG 5) (A). The Report indicated that the contribution could be made as these goals are relevant to Australia's underlying values and current challenges. For example, the significance of the SDGs was discussed in relation to indigenous peoples whose lives would be greatly affected by progress on the SDGs (A, D). Pursuing the SDGs was expected to result in social cohesion and sustainable growth at the domestic level and a reputation for being a role model at the international level (A).

The SDGs can shape diverse stakeholders' understanding and practice of sustainable development as a common framework (A). According to Impact Investing Australia, SDG investment funds and bonds are already in the market and investors are beginning to assess their performance against the SDGs. It is encouraging that the UN Principles for Responsible Investment was signed by 131 Australian companies and about $44 \%$ of investment was made following the principles (A). The noted growth in green bonds and environmental investment (96\% of impact investment) (A) can be also relevant to Australia which remains the highest per-capita greenhouse emitter in the OECD (D). On the other hand, the Australian public still shows low awareness on the SDGs as many still regard the SDGs as only relating to foreign aid (A). However, about $80 \%$ of Australian consumers did not want to buy anything from socially irresponsible companies and $72 \%$ found it important to work in a socially and environmentally responsible company as a laborer. This implies a possibility that Australian citizens can influence decision making in business.

The 2019 Report also identified potential benefits, opportunities and costs associated with implementation of the SDGs. Business-related possible benefits include strengthened corporate accountability, better risk management, improvement in communication skills with stakeholders, and stability of the market and society, as well as tangible 
outcomes such as $\$ 12$ trillion of market opportunities and 380 million new jobs in Australia (A). Noted potential business costs are related to staff training and introduction of innovative technology for the SDGs. Most companies and civil society perceived the costs rather as an investment for greater opportunities and returns.

Despite growing interests in SDGs, the necessity for more concerted efforts was acknowledged given that Australia was ranked $37^{\text {th }}$ globally by the SDG index (A). Australia seemed lacking a national implementation plan and monitoring system as well as long-term vision and strategies (A, D). The report recommended establishing a framework for regular monitoring and evaluation to ensure participation of government agencies, local governments and civil society.

\section{The Need for CSV in the SDG Era}

The Australian government acknowledged the critical role of businesses in financing and implementing the SDGs by driving economic growth, job creation, and technological development (A). The Report put an emphasis on partnership with civil society and the private sector in line with a goal for global partnership (Goal 17), discussing the Shared Value Project as an example. The Shared Value Project was established in 2014 by support from the Department of Foreign Affairs and Trade (DFAT) (A). It has played a key role in promoting shared value in Australia and the Asia Pacific in a regional partnership with the US based Shared Value Initiative (E). Currently, the Project has 27 members including community organizations and governmental agencies as well as businesses (E). More and more non-profit organizations join the group to transform themselves into social enterprises in the context of decreasing public fund and increasing demand for social services (B).

The Shared Value Project defines shared value as "a business strategy designed to solve social issues profitably" $(\mathrm{H})$ and "policies and practices that enhance the competitiveness of companies while improving social and environmental conditions in the regions where they operate” $(G)$. Shared value was distinguished from CSR which does not involve any direct returns from doing good or doing no harm (B), although some companies regarded it as complementary to CSR (G). The essence of shared value is the creation of economic benefits (E, G) and the connection among producers, consumers and laborers beyond shareholders (A, B). Creating shared value was believed to improve corporate sustainability with greater employee engagement, customer satisfaction and competitive advantage (G).

The SDGs were suggested to be a framework for coordinating companies' shared value activities (A). More than $90 \%$ of the Shared Value Project members believed that the SDGs are highly relevant to corporate value and operation, and $70 \%$ of member companies were actively embracing the SDGs in their business (A, E). However, they have found it challenging to measure the impact of shared value (B). 


\section{Shared Value in Practice to Be Aligned with the SDGs}

According to the Global Compact Network Australia, Australian companies are increasingly using the SDGs to communicate their work (A). However, the number of companies that report against the SDGs is still small and the quality of data is poor (A). Companies prefer improving existing policies and programs rather than aligning them with each goal (F). Australian companies are working on varied social issues including education, disability, indigenous disadvantage, homelessness and health in the name of creating shared value (B). It should be noted that many companies are addressing social and environmental concerns without referring to shared value. In addition, many of their CSV activities are not clearly related to the sector where the company belonged (G). It was observed that a company's efforts to imbed shared value and sustainable development are strongly associated with its vision and leadership (F).

Two Australian companies were chosen to examine how the SDGs and the concept of shared value were employed. One of the most frequently mentioned examples by the Shared Value Project is the Bendigo and Adelaide Bank (Bendigo). Bendigo won 2017 Shared Value Award and ranked 13th in the World in the Fortune Annual "Change the World" list of companies that are tackling society's unmet needs by doing business (H). In 1990s, one third of major Australian banks closed due to bank mergers. During this time, Bendigo increased the number of branches to address the exclusion and disempowerment of the affected communities by raising the funds from the community to open the branch, which remains locally owned and operated (H). Its Community Bank Model was established in 1998 in the framework of CSV with a focus on customer-focused culture, re-investment for the community, trusting relationship, stakeholder engagement and partnership (C). For example, Bendigo has delivered its Social Impact Loan Program since 2015 in partnership with community-owned social enterprises, which create opportunities for local employment in regional areas (H). Although the SDGs are not overtly used to describe the impact, Bendigo is contributing toward Goal 8 (Decent work and economic growth) and Goal 17 (Partnership for the goals) (E). Bendigo's model appears to contribute toward business growth with its point of difference $(\mathrm{H})$. Bendigo is now Australia's fifth largest retail bank with more over 1 million accounts and 320 local branches (C).

Another example is from the mining and extractive industry, which has been extensively criticized because of its negative impact on the environment and society. Probably as a response to growing criticism, the mining and extractive industry has tried to demonstrate its awareness of the SDGs and its efforts to improve its business practice. For example, it proposed a Framework for Sustainable Development named 'Enduring Value', which is to tailor the International Council on Mining and Metal's 10 principles of SDGs to Australian context (I). Cardno, 
a global infrastructure development firm, developed strategic shared value and disseminated information by hosting a UN SDGs roundtable in 2018 and publishing case studies in partnership with the Mineral Council of Australia (A, E). Cardno's report shows how the mining and extractive industry has worked on SDGs. Given that mining operations often take place on Indigenous land, Indigenous people's employment and business were supported, contributing to Goal 8 (Decent work and economic growth) and Goal 16 (Peace, justice and strong institutions) (F).

\section{Ways Forward}

More and more Australian companies are pursuing shared value and recognizing the relevance of the SDGs for their business practice. Despite this positive outlook, academics and civil society are still skeptical. There are still many companies which do not take the SDGs seriously or whose actions are not aligned well with the nation's priorities (A). Furthermore, such a move toward the SDGs was mainly observed in big companies. For example, transnational corporates were the first to integrate the SDGs into their operation because of their vulnerability to negative publicity and their flexibility for innovation (A). Small and medium enterprises (SMEs) stated, "We are a small business grappling with government regulation and costs...Your bureaucratic SDGs are of no relevance to this small business" (A, p. 96). Without incorporating the SDGs into the existing reporting scheme, a drive for the SDG-related reporting can burden poorly-resourced companies with additional cost (A).

Suggestions for creating an enabling environment was a recurring theme. A significant number of submissions by the private sector requested the government's tax incentives and support for adoption of shared value and alignment with the SDGs given the considerable amount of transaction cost (A, G). In addition, the government's stronger leadership was suggested as a key to coordination and prioritization (A, E). A suggestion for more enforceable requirements and greater engagement of civil society was made by research community to make companies accountable (A).

\section{DISCUSSION}

Findings of this present study represented a brief description of the extent to which shared value has been pursued in relation to the SDGs in Australia. The SDGs proposed comprehensive goals for economic growth, social development and environmental sustainability. The private sector was undertaking many activities to support the SDGs, including creating shared value (CSV) to enhance economic benefits and to improve social and environmental conditions at the same time. Businesses held expectations that the SDGs can offer the linkage between economic benefit and social and environmental impact when shared value is assessed. Not many Australian companies explicitly referred to the SDGs to communicate their performance and impact of CSV. This result is 
similar to existing studies which presented challenges facing by the private sector when implementing and assessing business practice in line with the SDGs [41]. Of note is that CSV is creating new opportunities for businesses. Given that banking and extractive industries have been heavily criticized for their social and environmental impacts, pursuing shared value can be a good opportunity for businesses to gain positive brand associations and to contribute to the SDGs [42]. This business potential can explain the extensive participation of the mining and mineral sector in establishment of the SDGs in the first place [8].

Considering the economic and social returns, Australian companies can be motivated to pursue social and environmental values to have great appeal for Australian people. The key document of this research claims that Australian values such as fairness and gender equality are closely aligned with social values (human rights, reducing inequality, climate justice) that underpin the SDGs. Achievement of the SDGs is also understood as significant for Australia, particularly for the marginalized populations including indigenous peoples who lag behind on most social and economic indicators. Such Australian values and culture can shape pro-sustainability orientation of the public, as demonstrated by its preference for socially and environmentally responsible companies as consumers, laborers and community members. This is in line with previous studies conducted internationally on the association between a country's culture and environmental performance [43] and between a culture of accountability and SMEs' proactive approach to corporate sustainability [44]. This implies that business practice towards the SDGs can be effectively nurtured where key social values are highly regarded.

One of the research questions to answer was to discern whether shared value and the SDGs are differently understood by stakeholders. This present study of the Australian context showed the worth of shared value as a strategy to promote multi-stakeholder partnership for the SDGs. Shared value appeared to bridge the gap in approaches to the SDGs between the public and the private sectors. However, the relationship between shared value and the SDGs is differently perceived. The private sector perceives the SDGs as a useful framework to steer and communicate its shared value interventions, whilst the public sector promoted shared value to improve business engagement with the SDGs. In addition, there is a discernible difference in the way civil society sees the current state of shared value. Civil society including the research community criticizes the instrumental approach of business to the SDGs and finds shared value neither ambitious enough nor enforceable. Existing studies also suggest the importance of enforceability for equality, climate justice and human rights realization as agreed by the SDG $[45,46]$. Differently from some studies which expressed serious concerns regarding neoliberal conceptualization and operationalization of the SDGs by corporate engagement [9], Australian civil society rather takes a pragmatic approach. Partnering with the private sector was suggested to 
improve business practice by offering its unique insight into the root causes of social and environmental issues and its better access to the marginalized groups [47]. Given that partnership often conceals some inherent differences and tensions between the private sector and other players [8], further study is warranted to elucidate the complexity of partnership.

The basic premise of this study is that pursuing shared value can advance the SDGs and this can be beneficial for companies as well as broader society. CSV was basically designed as a business strategy for corporate sustainability. However, large and transnational enterprises are more likely to adopt CSV and incorporate the SDGs into their business practice than SMEs. This confirms a previous study which observed the positive relationship between firm size and SDG-guided reporting [33]. Even though there is no clear understanding of shared value on which corporate decisions are grounded [21], system and organization theories can be of assistance as mentioned earlier. Organization theory explains companies' drive for shared value as a shift of focus from shareholders to stakeholders [48] and the shift is suggested as a response to the context in which companies face an increasing demand for sustainable development. According to a study on SMEs' perception of social responsibility in Australia, SMEs are more influenced by survival challenges than stakeholder perspective [49]. This suggests the importance of incentives and support for SMEs to encourage their engagement. This also confirms the need for increased attention to the role of government in creating the enabling environment as noted in previous studies as business's expectation of the role of governments [8].

\section{CONCLUSIONS}

The SDGs provoked discussion about businesses' roles for social and environmental sustainability as key players and partners with which to work. Shared value is a relatively new concept, which is related to the common goals for a just, equitable and sustainable world. This study illustrated the linkage between SDGs and shared value. Overall, it is evident that there is a growing awareness in Australia that businesses should actively engage in addressing social and environmental issues and that shared value can be an approach to such social demands. Findings from this research highlight the diversity and complexity in conceptualization and operationalization of shared value in relation to the SDGs. The potential implications of this research for policy and future research are twofold: First, this study suggests that further attention should be given to contextual influences on perceptions and practice of shared value, and second, this study suggests a need for concerted collaboration between the government, businesses and civil society. Advancing the SDGs can be supported by CSV when coordinated and monitored by the government and civil society with awareness of and commitment to social values for sustainability. 
Lastly, limitations of this study should be noted. Given the nature of a case study and the inherent complexity of shared value, the findings cannot be generalized. Comparative studies involving several countries would be useful for reflecting on contextual influences on conceptualization and operationalization of shared value. Given that documents are produced with a specific intention and audience, the possibility of discrepancies between written statements and business practice should be noted. It is hoped that future studies can capture the voices of multiple stakeholders from various sources. Finally, although beyond the scope of this research, an examination of the effects of CSV on people in the community, in particular those in developing countries, may have valuable implications for the implementation of shared value.

\section{DATA AVAILABILITY}

The dataset generated from the study can be found at websites of the Parliament of Australia, the Shared Value Project and mentioned companies.

\section{CONFLICTS OF INTEREST}

The author declares there is no conflict of interest.

\section{REFERENCES}

1. Kramer MR, Porter M. Creating shared value. Harvard Bus Rev. 2011;89(1/2):62-77.

2. Kim TK. Corporate Social Responsibility in the Era of 2030 Sustainable Development: Global Governance and Institutional Approach. Int Dev Coop Rev. 2017;9(1):7-31.

3. Hamilton A, Preston P. Shared value measurement. 2018. Available from: https://philpreston.com.au/wp-content/uploads/2018/09/sv-measurement-res ource-hamilton-preston-may18-final.pdf. Accessed on 2019 Nov 7.

4. Vildåsen SS. Corporate sustainability in practice: An exploratory study of the sustainable development goals (SDG s). Bus Strat Dev. 2018;1(4):256-64.

5. Mansell P, Philbin SP, Konstantinou E. 'Call to Arms': Using the Creating Shared Value Business Governance Paradigm to Deliver Projects' Business-Society Impact Against the UN SDG 2030 Targets. In: Proceedings of the EURAM (European Academy of Management 2019 Conference); 2019 Jun 26-28, Lisbon, Portugal.

6. Kim R. Can Creating Shared Value (CSV) and the United Nations Sustainable Development Goals (UN SDGs) Collaborate for a Better World? Insights from East Asia. Sustainability. 2018;10(11):4128-54.

7. Baxi U. Market fundamentalisms: business ethics at the altar of human rights. Human Rights Law Rev. 2005;5(1):1-26.

8. Scheyvens R, Banks G, Hughes, E. The private sector and the SDGs: The need to move beyond 'business as usual'. Sustaine Dev. 2016;24(6):371-82. 
9. Weber H. Politics of 'leaving no one behind': contesting the 2030 Sustainable Development Goals agenda. Globalizations. 2017;14(3):399-414.

10. Andreotti V, Souza LM, Editors. Postcolonial perspectives on global citizenship education. New York (NY, US): Routledge; 2011.

11. Meath C. The Future of Corporate Reporting. AIBE Industry Research Series. 2018. Available from: https://aibe.uq.edu.au/article/2018/11/corporatereporting-australia-set-change. Accessed on 2019 Oct 31.

12. Karp DJ. Responsibility for Human Rights: Transnational Corporations in Imperfect States. Cambridge (UK): Cambridge University Press; 2014.

13. Andrews N. Community expectations from Ghana's new oil find: conceptualizing corporate social responsibility as a grassroots-oriented process. Afr Today. 2013;60(1):54-75.

14. Aguirre D. The Human Right to Development in a Globalized World. Hampshire (UK): Ashgate Publishing; 2008.

15. den Hond F, de Bakker FG, Neergaard P. editors. Managing Corporate Social Responsibility in Action: Talking, Doing and Measuring. Hampshire (UK): Ashgate Publishing; 2007.

16. Aguinis H, Glavas A. What we know and don't know about corporate social responsibility a review and research agenda. J Manag. 2012;38(4):932-68.

17. Subba D, Rao MK. Measuring the Effects of CSR on Compassion at Workplace: An Empirical Study in North East Region of India. Purushartha J Manag Ethics Spirit. 2016;9(1):26-42.

18. Frynas JG. The false developmental promise of corporate social responsibility: Evidence from multinational oil companies. Int Aff. 2005;81(3):581-98.

19. Blowfield M. Corporate social responsibility: reinventing the meaning of development? Int Aff. 2005;8(3):515-24.

20. Conroy ME. Can advocacy-led certification systems transform global corporate practices? Evidence, and some theory. Amherst (MA, US): University of Massachusetts; 2001.

21. Dembek K, Singh P, Bhakoo V. Literature review of shared value: A theoretical concept or a management buzzword? J Bus Ethics. 2016;137(2):231-67.

22. Koo JW, Kim YL, Kim DW. From Global Philanthropy to Creating Shared Values: Rethinking Public-Private Partnership in International Development Cooperation. J Int Area Stud. 2014;24(1):75-113.

23. Carroll A. Corporate social responsibility evolution of a definitional construct. Bus Soc. 1999;38(3):268-95.

24. Wójcik P. How Creating Shared Value Differs From Corporate Social Responsibility. Manag Bus Admin. 2016;24(2):32-55.

25. Fukuda-Parr S. From the Millennium Development Goals to the Sustainable Development Goals: shifts in purpose, concept, and politics of global goal setting for development. Gender Dev. 2016;24(1):43-52.

26. Sachs JD. From millennium development goals to sustainable development goals. Lancet. 2012;379:2206-11. 
27. Lee SH. Sustainable Development Goals and rights-based approach to development. J Int Dev Coop. 2017;12(4):3-38.

28. OHCHR (Internet). Available from: https://www.ohchr.org/EN/Issues/SDGS/ Pages/The2030Agenda.aspx. Accessed 2020 Feb 17.

29. van Zanten JA, van Tulder R. Multinational enterprises and the Sustainable Development Goals: An institutional approach to corporate engagement. J Int Bus Policy. 2018;1(3-4):208-33.

30. Freistein K, Mahlert B. The potential for tackling inequality in the Sustainable Development Goals. Third World Q. 2016;37(12):2139-55.

31. Bell D. Climate change and human rights. Wiley Interdiscip Rev Clim Change. 2013;4(3):159-70.

32. Kotzé LJ. Human rights and the environment in the Anthropocene. Anthropocene Rev. 2014;1(3):252-75.

33. Rosati F, Faria LGD. Business contribution to the Sustainable Development Agenda: Organizational factors related to early adoption of SDG reporting. Corp Soc Res Environ Manag. 2019;26(3):588-97.

34. da Costa D, McMichael P. The poverty of the global order. Globalizations. 2007;4(4):588-602.

35. Bausch KC. The emerging consensus in social systems theory. New York (NY, US): Kluwer academics/Plenum Publisher; 2001.

36. Mills AJ, Simmons T, Helms Mills JC. Reading organization theory: A critical approach to the study of organisational behaviour and structure. Ontario (Canada): Garamond Press; 2005.

37. Astley WG, Van de Ven AH. Central perspectives and debates in organization theory. Admin Sci Q. 1983;28(2):245-73.

38. Yin RK. Case study research: Design and methods. Thousand Oaks (CA, US): Sage Publications; 2009.

39. Ritchie J, Lewis J. Qualitative research practice: A guide for social science students and researchers. Thousand Oaks (CA, US): SAGE; 2003.

40. Woodhouse LD. Thematic analysis of documents from the SOPHE Health Disparity Elimination Research Agenda Summit: Illuminating competencies for future researchers and practitioners. Health Promot Pract. 2006;7(3):346-53.

41. Arnold MG, Skjerven A, Schneider K. Introduction to the special issue on "The role of SDGs for progressing sustainability". Bus Strat Dev. 2018;1(4):228-9.

42. Fraser J. Creating shared value as a business strategy for mining to advance the United Nations Sustainable Development Goals. Extr Ind Soc. 2019;6(3):788-91.

43. Kumar S, Giridhar V, Sadarangani P. A cross-national study of environmental performance and culture: Implications of the findings and strategies. Global Bus Rev. 2019;20(4):1051-68.

44. Galeitzke M, Orth R, Kohl H. Sustainability Strategies in German Small and Medium-Sized Companies. J Sustain Res. 2019;4(3):1-15.

45. Choondassery Y. Rights-based Approach: The Hub of Sustainable Development. Discourse Commun Sustain Educ. 2017;8(2):17-23. 
46. Winkler IT, Williams C. The Sustainable Development Goals and human rights: a critical early review. Int J Human Rights. 2017;21(8):1023-8.

47. Social Ventures Australia (Internet). The journey of creating shared value. Available from: https://www.socialventures.com.au/sva-quarterly/thejourney-of-creating-shared-value/. Accessed 2020 May 15.

48. Andersen JA. How organisation theory supports corporate governance scholarship. Corp Govern. 2015;15(4):530-45.

49. Sen S, Cowley J. The relevance of stakeholder theory and social capital theory in the context of CSR in SMEs: an Australian perspective. J Bus Ethics. 2014;118(2):413-27.

How to cite this article:

Noh J-E. Promotion of Shared Value for the SDGs (Sustainable Development Goals): A Case Study of Australia. J Sustain Res. 2020;2(3):e200025. https://doi.org/10.20900/jsr20200025 